\title{
Bir Hastanenin Aile Hekimliği Polikliniğine Başvuran Hastaların Sigara İçme Durumları: Ankara Örneği
}

\section{Smoking Among Patients Who Applied to Family Practice Outpatients of a Hospital: Ankara Sample}

\author{
Zekai Uysal ${ }^{1}$, Ertuğrul Hatipoğlu² \\ ${ }^{1}$ Sağlık Bilimleri Üniversitesi, Dışkapı Yıldırım Beyazıt Eğitim ve Araştırma Hastanesi, Aile Hekimliği Kliniği, Uzman Doktor \\ ${ }^{2}$ Hacettepe Üniversitesi, İktisadi ve Idari Bilimler Fakültesi, Sosyal Hizmet Bölümü, Araştırma Görevlisi
}

\section{ÖZ}

Amaç: Aile Hekimliği Polikliniğine başvuran hastaların sigara içme durumları ve nikotin bağımllık seviyelerinin sosyo-demografik değişkenlerle arasındaki ilişkinin incelenmesi amaçlanmıştır.

Yöntem: Bu kesitsel, niceliksel araştırmada uygunluk örneklemi kullanıımıştır. Bu araştırma 01.02.2018-01.04.2018 tarihleri arasında Dışkapı Yıldıım Beyazıt Eğitim ve Araştırma Hastanesi Aile Hekimliği Polikliniği'nde yürütülmüştür. Polikliniğe başvuran hastalar arasından, araştırmaya katımayı kabul edenler ile görüşmeler yapılmıştır. Araştırmacılar verileri hastalarla yüz yüze görüşerek elde etmiştir. Verilerin toplanmasında demografik bilgi formu ve Fagerström Nikotin Bağımlılık Testi (FNBT) kullanılmıştır. Elde edilen veriler SPSS v. 20 programı ile araştırmanın amacı doğrultusunda incelenmiş̧tir. Sürekli değişkenler ortalama ya da standart sapma, kategorik değişkenler ise sıkık, yüzdelik değerlerle ifade edilmiştir. Analizıerde $p<0.05$ değeri anlamlıık sınırı olarak belirlenmiştir.

Bulgular: 177 hasta ile yapılan görüşmelerde; 97 'si $(\% 54,8)$ erkek, 80 i $(\% 45,2)$ kadındır. Hastaların yaş ortalaması 39 'dur ve cinsiyetler arasında anlamlı farklıık görülmemektedir. Hastaların 83 'ü $(\% 46,9)$ hiç sigara içmediğini, 26 'sı $(\% 14,7)$ daha önce sigara içmiş ancak bıraktığını, 66'sı $(\% 37,3)$ aktif olarak sigara kullandığını ve 2 hasta ise pasif içici konumda olduğunu ifade etmiştir. Hastalarda sigaraya başlama yaşı ortalama 18 'dir ve cinsiyetler arasında anlamlı bir fark bulunmamaktadır $(p>0.05)$. Kadınlar ve erkekler arasında bağımllık derecesini gösteren nikotin bağımlıık puanları arasında anlamlı bir fark yoktur $(p>0.05)$. Sigara kullanan 66 hastanın \%25'i hafif derecede nikotin bağımlısı, \%36,4'ü orta derecede nikotin bağımlısı, \%34,8'i şiddetli nikotin bağımlısı ve \%3'ü çok şiddetli nikotin bağımlısıdır. Cinsiyetle sigara içme durumu arasında anlamlı bir ilişki tespit edilmiştir, erkeklerin sigara içme durumunun kadınlara göre daha sık olduğu bulunmuştur $(p<0,05)$. Günlük sigara kullanımı ile sigaraya başlama yaşı arasında pozitif bir korelasyon tespit edilmiştir. Günlük sigara kullanım miktarı ile cinsiyet arasında anlamlı bir ilişki yoktur $(p>0.05)$. Sigara kullananların \%72'si sigarayı bırakmayı düşünürken, \%28'i bırakmayı düşünmediğini ifade etmiştir.

Sonuç: Hastaların sigara içme durumlarının incelendiği bu çalışmada bağımlıık düzeyi ile cinsiyet arasında anlamlı bir fark bulunmamıştır. Erkekler ile kadınlar arasında sigara içme yoğunluğuna bakıldığında, erkekler arasında sigara içme durumu daha sık karşılaşılan bir durumdur. Erkeklerin \%60'ı sigara kullanırken kadınlarda bu oran $\% 26$ 'dır. Sigara içenlerin büyük çoğunluğu bırakmak istediğini ifade etmiştir.

\begin{abstract}
Objective: The aim of this study was to investigate the relationship between the socio-demographic variables and nicotine dependence levels of the patients who applied to the Family Medicine Outpatient Clinic.
\end{abstract}

Methods: The convenience sampling method was used in this cross-sectional quantitative research. This research was carried out at Dışkapı Yıldırım Beyazıt Training and Research Hospital Family Medicine Polyclinic between 01.02.2018 and 01.04.2018. Among the patients who applied to the outpatient clinic, interviews were conducted with those who accepted to participate in the study. The researchers obtained the data from the patients face to face. Demographic data form and Fagerstrom Nicotine Addiction Test (FNBT) were used for data collection. The data obtained were analyzed by SPSS v. 20 program and the purpose of the study was examined. Continuous variables are expressed as mean or standard deviation, categorical variables are expressed as frequency and percentage. $p<0.05$ value was determined as the significance level.

Results: During the interviews with 177 patients; 97 (54.8\%) male and $80(45.2 \%)$ female. The mean age of the patients was 39 and there was no significant difference between the genders. Eight of the patients $(46.9 \%)$ had never smoked, $26(14.7 \%)$ had previously smoked, but $66(37.3 \%)$ had been smoking and 2 had passive smoking. stated. The mean age of starting smoking was 18 and there was no significant difference between the genders $(p>0.05)$. There was no significant difference in nicotine dependence scores between males and females ( $p>0.05$ ). Of the 66 patients who were smoking, $25 \%$ were mildly nicotine-dependent, $36.4 \%$ were moderate nicotine-dependent, $34.8 \%$ were severe nicotinedependent and $3 \%$ were very severe nicotine-dependent. A significant relationship was found between sex and smoking status and males were more frequently compared to females $(p<0.05)$. There was a correlation between daily smoking and smoking age. There was no significant relationship between sex and daily smoking ( $p>0.05$ ). While $72 \%$ of smokers thought to quit smoking, $28 \%$ stated that they did not intend to quit.

Conclusion: In this study where smoking status of the patients were examined there was no significant difference between sex and addiction level in this study. When smoking intensity is observed among males and females, smoking is more common among males. While $60 \%$ of men smoke, this rate is $26 \%$ in women. The majority of smokers stated that they wanted to leave.

Keywords: Family practice, Nicotine dependence, Smoking

Gönderme tarihi / Received: 09.11.2018 Kabul tarihi / Accepted: 13.12.2018

İletişim: Zekai Uysal, Dışkapı Yıldırım Beyazıt Eğitim ve Araştırma Hastanesi, Aile Hekimliği Kliniği,ANKARA

Tel: 0 (505) 9437110 E-posta: zekaiuysal33@yahoo.com.tr 


\section{GíRiş}

Nikotin bağımlılığı, sigara içme davranışının sürdürülmesi ve tedaviye yönelik müdahalelerin genel başarısızlığı olarak ifade edilmektedir (1). Tütün kullanımının, bireylerin sağlık durumlarına olumsuz etkilerinin olduğu 20. yüzyılın ikinci yarısında açıkça ortaya konmaya başlamıştır (2, 3). Bu döneme kadar tütün; Tütün Kesilme Sendromu henüz kabul edilmemiş olduğu için bağımlılık yapıcı bir madde olmaktan çok, alışkanlık yapan bir madde olarak kabul edilmekteydi (4). Yarım yüzyıl öncesinde yapılan çalışmalar, sigara içenlerin yalnızca \%10'unun günde beş taneden daha az sayıda sigara kullandıkları, diğerlerinin ise zamanla sigara kullanım miktarını arttırdıklarını göstermiştir. Yine aynı dönemde yapılan çalışmalarda, sigara içme tutumlarının kişiler arasında tutarlı bir seyir izlediği ve içenlerin çoğunluğunun sigarayı bırakmak istemelerine rağmen içmeye devam ettiklerini gösteren bilimsel verilerin elde edilmesi, nikotin bağımlığının çerçevesini çizmiştir (5).

Amerikan Psikiyatri Birliği'nin kriterlerine göre (DSM IV); son bir yıl içerisinde aşağıdaki yedi maddeden en az üçüne sahip kişilere Nikotin Bağımlılığı tanısı konmaktadır.

1. İstenilenden fazla miktar ve sürede kullanmak

2. Bırakma isteği bulunmasına rağmen girişimlerin başarısız sonuçlanması

3. Kullanım için fazla vakit harcamak

4. Sosyal etkinlikleri ve diğer zevk verici faaliyetleri terk etmek
5. Kullanılan maddeye bağlı fiziksel ve psikolojik rahatsızlıklara rağmen kullanımı devam ettirmek

6. Tolerans geliştirmek

7. Yoksunluk belirtisi göstermek.

Sigara içmek, önlenebilir hastalıkların ve erken ölümlerin en önemli nedenleri arasında olduğu için önemli bir halk sağlığı problemidir (7). Dünya Sağlık Örgütü (WHO) tarafından yayınIanan Tütün Atlası Raporu'na (8) göre, Türkiye'de her yıl 65.300 kişi sigaraya bağlı hastalıklardan dolayı yaşamını yitirmesine rağmen, 10-14 yaş arası 186.000 çocuk ve yaklaşık 15 milyon yetişkin günlük sigara kullanımına devam etmektedir. Ölüm oranlarına bakıldığında Türkiye, Kuzey Kore'den hemen sonra, en yüksek tütün kaynaklı ölüm oranına sahip ikinci ülke konumundadır.

Türkiye'de günlük sigara kullanımının başladığı yaş ortalaması 17,1 'dir. Erkeklerde yaş ortalaması 16,8 iken kadınların ortalama bir yıl $(17,9)$ geç sigaraya başladığı görülmektedir. Her gün sigara içenlerin büyük kısmı $(\% 70,4)$ günde 11 ve daha fazla sayıda sigara içmektedir ve günlük ortalama sigara tüketimi ise 19,2 adettir. Sigara içenlerin \%42,1'i uyanmayı takip eden otuz dakika içerisinde ilk sigaralarını içmektedir (9). Türkiye'de giderek büyüyen bir endüstri olan tütün, en önemli halk sağlığı sorunlarından biri olarak karşımıza çıkmaktadır.

Türkiye'de 1990'lardan başlayarak, önleyici halk sağlığı çalışmaları çerçevesinde, tütün kullanımı ile mücadele uygulamaları hayata geçiril- 
miştir. Bu uygulamalardan biri olarak tütün kontrol yasası da bu yıllarda yürürlüğe girmiştir. Aynı dönemde Dünya Sağlık Örgütü’nün Tütün Kontrolü Çerçeve Sözleşmesi'ne Türkiye taraf olmuş ve 2008 yılında da önlemlerin kapsamı genişletilmiştir (10).

Türkiye'de sigara kullanımı ve nikotin bağımlııı̆ı alanında birçok araştırma yapılmıştır. Celepkolu ve arkadaşları (11) Diyarbakır'da, Sunay ve arkadaşları ise (12) Ankara'da Aile Hekimliği'ne başvuran hastalarda sigara bağımlılık düzeyini cinsiyet ve yaş gibi çeşitli değişkenlere göre incelemişlerdir. Özşahin ve arkadaşları (13) Aile Hekimliği Polikliniği'ne başvuran sigarayı bırakmış hastaların, sigarayı bırakmalarında etkili olan faktörleri incelemiştir. Zincir ve arkadaşları (14) Sigara Bırakma Polikliniği'ne başvuran hastaların mizaç ve karakter özelliklerinin sigarayı bırakma davranışı üzerine etkisini araştırmıştır. Karadağlı ve Nahcivan (15) hastaların nikotin bağımlılık düzeyleri ile sigarayı bırakmaya hazır oluş durumları arasındaki ilişkiyi incelemiştir. Kutlu ve Çivi (16) lise öğrencilerinde sigara içme sıklığını araştııırken, Akpınar ve arkadaşları (17) üniversite birinci sınıf öğrencilerinin sigara içme durumları ile kişisel uyumları arasındaki bağlantıyı araştırmıştır. Yengil ve arkadaşları (18) tıp fakültesi öğrencileri arasındaki nikotin bağımlılık düzeylerini Fagerström Nikotin Bağımlıık Testi (FNBT) ile incelemiştir. Kutlu ve arkadaşları (19) hemşireler arasında sigara içme durumlarını ve etkileyen faktörleri araştırmıştır. Tezcan ve Yardım (20) aralarında doktor, hemşire ve tıp fakültesi öğrencilerinin bulunduğu sağlık çalışanları arasında sigara içme tutumunu araştırırken, Mevsim ve arkadaşları (21) sağlık çalışanlarında sigara içme tutumu ve kansere yönelik önlemler arasındaki ilişkiyi araştırmıştır. Öztürk ve arkadaşları (22) sigarayı önlemeye ilişkin yasal düzenlemelerin sağlık personelinin sigara içme tutumlarına etkisini incelemiştir 19).

Sigara kullanımı ile mücadele, farklı disiplinlerin birlikte ve koordinasyon içinde hareket etmesiyle ancak olumlu sonuçların alınabileceği bir konudur. Aile Hekimleri multidisipliner ekip çaışmasının parçası olarak, sigara bağımlılığı alanında koruyucu ve önleyici çalışmalar için vazgeçilmez bir unsur olarak karşımıza çıkmaktadır. Aile Hekimliği Poliklinikleri; sigara bağımlıığı ile mücadele pratiğinde, birinci basamak sağlık hizmetleri kapsamında hastaları bilgilendirici ve önleyici çalışmalar yapmak için, en uygun uygulama sahası olarak kabul edilmelidir. Etkili çalışmaların yapılabilmesi için bilimsel bilgilerin üretilmesi önem taşımaktadır. Aile Hekimliği Polikliniklerinin bulundukları bölgelerde bilimsel kanıt üretme çabaları, soruna yönelik müdahale planlamasını da şekillendirecektir.

$\mathrm{Bu}$ çalışmanın amacı, birinci basamak sağlık hizmeti sunan Aile hekimliği Polikliniği'ne başvuran hastaların nikotin bağımlılık durumlarının incelenmesidir. Sigara kullanan hastaların sosyo-demografik özellikleri çerçevesinde nikotin bağımlığı hakkında betimsel bilgilere ulaşıması, koruyucu önleyici çalışmalar açısından yol gösterici olacaktır. 


\section{GEREÇ VE YÖNTEM}

Bu çalışma gözlemsel, tanımlayıcı ve prospektif bir çalışma olup, araştırmanın amacına uygunluğu nedeniyle niceliksel metodolojiye dayalı genel tarama modeli kullanılarak gerçekleştirilmiştir. Araştırmanın kesitsel bir araştırma olması nedeniyle, katılımcılar T.C. Sağlık Bakanıı̆ı, Sağlık Bilimleri Üniversitesi, Dışkapı Yıldırım Beyazıt Eğitim ve Araştırma Hastanesi, Aile Hekimliği Polikliniği'ne 01.02.2018-01.04.2018 tarihleri arasında herhangi bir nedenden dolayı başvuran hastalardan oluşmuştur. Araştırmanın uygulanmasına başlarken hastalardan etik onay alınmıştır. Veriler, hastalarla yüz yüze görüşme yapılarak araştırmacılar tarafından toplanmıştır. Okur yazarlığı olmayan 10 katılımcıya tüm sorular araştırmacılar tarafından okunmuştur. Veri toplama aracı olarak araştırmanın amacı doğrultusunda, araştırmacılar tarafından hazırlanan Sosyo-demografik Bilgi Formu ve nikotin bağımlılık düzeyi ölçme aracı olan Fagerström Nikotin Bağımlılık Ölçeği (FNBT) kullanıımıştır.

Sosyo-demografik bilgi formunda hastalara sorulan, yaş, cinsiyet, sigara içme durumları, hanede sigara içen kişi sayısı, kaç yıldır sigara içtiği gibi sorular bulunmaktadır.

Görüşme formunun diğer bileşeni ise Fagerström Nikotin Bağımlılık Ölçeği, Fagerström ve arkadaşları tarafından geliştirilen sigara içen bireylerde nikotin bağımlılığının derecesini ölçmeye yarayan 6 sorudan oluşan bir tarama testidir. Sorulara verilen cevaplar 0-3 arasında değerler almaktadır. Teste verilen tüm soruların değerleri toplandığında bağımlılık derecesi belirlenmektedir. Ölçeğin Türkçeye uyarlanması Uysal ve arkadaşları (23) tarafından yapılmıştır. Ölçekten alınabilecek en düşük puan 0 (sıfır), en yüksek puan ise 10 (on)'dur. Ölçekten elde edilen toplam puanlara göre bağımlılık derecesinin sınıflandırılması şu şekildedir; 0-4 puan düşük bağımlıık, 5-6 puan orta bağımlııı, 7-8 puan yüksek derece bağımlılık ve 9-10 puan çok şiddetli bağımlıııktır (11).

Araştırma verilerinin istatistiksel analizleri SPSS (v.20) programı ile yapılmıştır. Ölçümsel değişkenler ortalama ve frekans ile kategorik değişkenler ise sayı $(\mathrm{N})$ ve yüzde (\%) ile sunulmuştur. Verilerin normal dağılım gösterip göstermedikleri Kolmogrov-Smirnov testi ile kontrol edilmiştir. Spearman Korelasyon analizi ve Mann Whitney-U testi kullanılmıştır. $p<0.05$ anlamlılık sınırı olarak kabul edilmiştir.

\section{BULGULAR}

Araştırma, T.C. Sağlık Bakanlığı, Sağlık Bilimleri Üniversitesi, Dışkapı Yıldırım Beyazıt Eğitim ve Araştırma Hastanesi, Aile Hekimliği Polikliniği'ne Şubat-Nisan 2018 tarihleri arasında başvuran ve araştırmaya katılmayı kabul eden 177 hasta ile gerçekleştirilmiştir. Araştırmaya katılanların demografik özelliklerine bakıldığında, 97'si (\%54,8) erkek, 80'i (\%45,2) kadındır. Tüm hastaların yaş ortalaması 39'dur ve cinsiyetler arasında anlamlı farklılık görülmemektedir. Hastaların demografik özellikleri Tablo1'de gösterilmiştir. 


\begin{tabular}{|l|c|c|}
\hline \multicolumn{3}{|c|}{ Tablo 1. Hastaların Demografik Özellikleri } \\
\hline & n & $\%$ \\
\hline Cinsiyet & & \\
\hline Kadın & 97 & $54,8 \%$ \\
\hline Erkek & 80 & $45,2 \%$ \\
\hline Eğitim durumu & & \\
\hline Okuryazar değil & 10 & $5,6 \%$ \\
\hline Okuryazar & 4 & $2,3 \%$ \\
\hline İlköğretim & 76 & $42,9 \%$ \\
\hline Lise & 60 & $33,9 \%$ \\
\hline Üniversite & 27 & $15,3 \%$ \\
\hline
\end{tabular}

Hastaların sigara içme durumuna bakıldığında (Tablo 2) 83'ü $(\% 46,9)$ hiç sigara içmediğini, 26 'sı (\%14,7) daha önce sigara içtiğini ancak şu an kullanmadığını, 66'sı $(\% 37,3)$ aktif olarak sigara kullandığını ve 2 hasta ise pasif içici konumda olduğunu ifade etmiştir. Hastalar ortalama $15(S S=12,6)$ yıldır sigara içmektedir. Sigara içme süresi cinsiyetler arasında benzerdir. Eğitim seviyesi ile sigara içilen toplam yıl arasında negatif bir korelasyon vardır $(r=-0.409$, $p<0.001)$.

\begin{tabular}{|l|c|c|}
\hline \multicolumn{3}{|c|}{ Tablo 2. Hastaların Sigara İçme Durumları } \\
\hline & $\mathbf{n}$ & $\%$ \\
\hline Hiç içmemiş & 83 & $46,9 \%$ \\
\hline İçmiş bırakmış & 26 & $14,7 \%$ \\
\hline Halen içiyor & 66 & $37,3 \%$ \\
\hline Pasif içici & 2 & $1,1 \%$ \\
\hline
\end{tabular}

Hastalarda sigaraya başlama yaşı erkeklerde ortalama 18, kadınlarda ortalama 19'dur. En düşük değer 7, en yüksek değer 49'dur ve cinsiyetler arasında anlamlı bir fark bulunmamaktadır. Erkek ve kadın katılımcılar arasında sigara içme sıklığına bakıldığında, erkeklerde sigara bağımlıığı daha sık görülmektedir. Erkeklerin $\% 60,6$ 'sı ( $\mathrm{N}=40$ ) sigara içerken, kadınların \%39,4'ü (N=26) sigara kullanmaktadır.
Nikotin bağımlılarının, nikotin bağımlılık ölçeğinden aldıkları ortalama puan 3,62'dir. Sigara içen hastalar bağımlılık derecelerine göre sınıflandırıldığında: sigara kullanan 66 hastanın, \%25’i $(\mathrm{N}=17)$ hafif derecede nikotin bağımlısı, $\% 36,4$ 'ü ( $N=24)$ orta derecede nikotin bağımlısı, \%34,8'i ( $N=23)$ şiddetli nikotin bağımlısı ve \%3'ü (N=2) çok şiddetli nikotin bağımlısıdır. Sigara kullanan kişiler arasında, nikotin bağımlılık düzeylerinin cinsiyete göre karşılaştırılması için Tablo 3'e bakınız.

\begin{tabular}{|c|c|c|c|c|}
\hline & \multicolumn{2}{|c|}{ Kadın } & \multicolumn{2}{|c|}{ Erkek } \\
\hline & $\mathbf{n}$ & $\%$ & $\mathbf{n}$ & $\%$ \\
\hline \multicolumn{5}{|l|}{$\begin{array}{l}\text { Nikotin Bağımlılık } \\
\text { Düzeyi }\end{array}$} \\
\hline $\begin{array}{l}\text { Hafif derecede nikotin } \\
\text { bağımlısı }\end{array}$ & 8 & $30,8 \%$ & 16 & $\begin{array}{c}40,0 \\
\%\end{array}$ \\
\hline $\begin{array}{l}\text { Orta derecede nikotin } \\
\text { bağımlısı }\end{array}$ & 12 & $46,2 \%$ & 11 & $\begin{array}{c}27,5 \\
\%\end{array}$ \\
\hline $\begin{array}{l}\text { Şiddetli nikotin } \\
\text { bağımlısı }\end{array}$ & 1 & $3,8 \%$ & 1 & $2,5 \%$ \\
\hline $\begin{array}{l}\text { Çok şiddetli nikotin } \\
\text { bağımlısı }\end{array}$ & 5 & $19,2 \%$ & 12 & $\begin{array}{c}30,0 \\
\%\end{array}$ \\
\hline
\end{tabular}

Sigara içen hastaların, nikotin bağımlılık puanları ile cinsiyetleri arasında anlamlı bir ilişki yoktur. Nikotin bağımlılık puanları ile sigaraya başlama yaşı arasında, korelasyon yoğunluğu ortalama ve negatif yönlü bir ilişki vardır ( $r=-0.445$, $p<0.01)$. Sigaraya başlama yaşı düştükçe nikotin bağımlılık seviyesi yükselmektedir. Nikotin bağımlılık şiddeti ile eğitim seviyesi arasında doğrusal anlamlı bir ilişki bulunmamaktadır. Nikotin bağımlılık puanları ile evde sigara içen kişi sayısı arasında anlamlı bir ilişki bulunmamaktadir. 
Günlük sigara kullanım miktarı ile cinsiyet arasında anlamlı bir ilişki yoktur ( $p>0.05)$. Günlük sigara kullanım miktarı ile eğitim seviyesi ( $p>0.05$ ) ve evde sigara içen kişi sayı arasında doğrusal bir ilişki bulunmamaktadır. Sigaraya başlama yaşı azaldıkça günlük sigara kullanım miktarı artmaktadır $(r=-0.370, p<0.005)$. Sigara Kullananların günlük kullandığı sigara miktarları Tablo 4'te verilmektedir. \%17,5'i günlük on taneden az sigara içerken, \%14'ü yaklaşık bir paket sigara (20 tane) içmektedir. Sigara kullananların \%72'si sigarayı bırakmayı düşünürken, \%28'i bırakmayı düşünmediğini ifade etmiştir.

Sigara içenler arasında sigarayı bırakmayı düşünüp düşünmedikleri sorusuna verilen yanıtlara bakıldığında, kadınların \%66'sı erkeklerin \%76'sı bırakmayı düşündüğünü ifade etmiştir (Tablo 5). Bırakmayı deneme ortalaması yaklaşık 2'dir ve cinsiyetler arasında anlamlı bir fark yoktur $(p>0.05)$.

\begin{tabular}{|c|c|c|}
\hline & $\mathbf{n}$ & $\%$ \\
\hline \multicolumn{3}{|l|}{ Sigara İçenler } \\
\hline On taneden az sigara & 31 & 17,5 \\
\hline On bir-yirmi arası sigara & 25 & 14,1 \\
\hline Yirmi bir-otuz arası sigara & 4 & 2,3 \\
\hline Otuz bir ve üzeri sigara & 7 & 4,0 \\
\hline Toplam & 67 & 37,9 \\
\hline Sigara içmeyenler & 110 & 62,1 \\
\hline Toplam & 177 & 100,0 \\
\hline
\end{tabular}

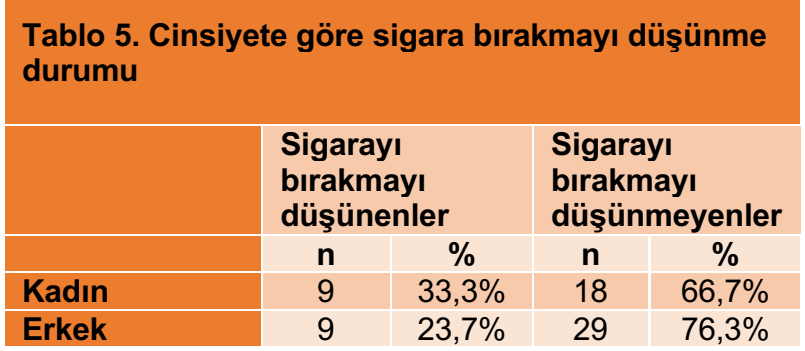

\section{TARTIŞMA}

Aile Hekimliği Polikliniği'ne başvuran hastalar arasında sigara kullanımı ve nikotin bağımlılık seviyesini araştırdığımız bu çalışmada, sigara içmeye başlama yaşının günlük içilen sigara miktarını etkilediği bulunmuştur. Erkeklerde sigara içme seviyesinin yüksek olması ataerkil toplum yapısının sigarayı eril bir simge olarak sunmasından kaynaklanıyor olabilir. Bu çalışmada eğitim seviyesi ile nikotin bağımlılığı arasında doğrudan bağlantı kurulamasa da, daha büyük örneklem grubu ile yapılan çalışmalarda eğitim seviyesi ile bağımlılık korelasyonu pozitif yönlüdür. Bunun nedenleri arasında eğitim seviyesi yükseldikçe kişilerin fiziki olarak daha az yoğun ancak ruhsal açıdan daha stresli iş ve mesleklerde çalışması etkili olabilir.

Araştırma bulgularına göre sigara içmeye başlama yaşı ortalama 18 olarak bulunmuş ve kadınlarla erkekler arasında anlamlı bir fark görülmemiştir. Genç insanların sağlıkları ve yaşam koşulları konusundaki risklere ilişkin daha az endişe duymaları ve riskli davranışlara daha fazla meyilli olmaları dışında, reklam ve toplumsal kabullere yatkınlıklarının daha yüksek olması nedeniyle, gençlik devresi sigaraya başlama riskini arttıran bir durum olarak karşımıza 
çıkmaktadır (24). Türkiye'de sigara içenlerin büyük çoğunluğu (\%83) 21 yaşından önce sigaraya başlamaktadır. Bu dönemin önemli özelliklerinden olan aile bireylerini ya da ünlü şahsiyetleri örnek almak sigara kullanımın başlangıcında etkili olabilir (2). Sağlık Bakanlığı'nın 2012 yılında yaptığı Küresel Yetişkin Tütün Araştırması'na göre erkeklerle kadınlar arasında sigaraya başlama yaşı ortalaması bir yıllık farklılık göstermektedir. Bu araştırmaya göre kadınlar erkeklerden bir yıl daha geç sigara içmeye başlamaktadır. Yine bu araştırmada her iki cinsiyet için ortalama sigaraya başlama yaşı 17,1 olarak tespit edilmiş ve sigaraya başlama yaşı ortalaması her iki cinsiyet için birbirine yakın bulunmuştur.

Cinsiyetler arasında sigara kullanma sıklığı ve miktarına bakıldığında, erkekler arasında sigara içme durumu hem daha sık hem de günlük içilen sigara miktarı daha fazladır. Benzer bir araştırmada erkekler arasında sigara içme durumu kadınlara göre 3 kat daha fazla bulunmuştur (11). PIAR'ın (25) araştırmasına göre ülkemizde erkeklerin \%62,8'i, kadınların \%24,3'ü sigara kullanmaktadır. Hastane çalışanlarında yapılan bir araştırmada da sigara tüketim miktarı erkeklerde kadınlara göre daha fazla bulunmuştur (26).

Araştırmanın sonuçlarına göre nikotin bağımlılık seviyesi ile cinsiyet ve eğitim durumu arasında anlamlı bir ilişki bulunamazken, sigara başlama yaşının bağımlılık şiddeti üzerinde etkili olduğu bulunmuştur. Özellikle erken yaşta sigara iç- meye başlayanların, daha uzun süreli sigara içmelerinden dolayı daha şiddetli bağımlılık seviyesine ulaştıkları ve ayrıca günlük daha fazla sigara içtikleri yorumu yapılabilir. Diyarbakır ve Ankara örnekleminde yapılan benzer çalışmalarda da cinsiyet ve eğitim durumu ile nikotin bağımlılık şiddeti arasında ilişki bulunmamıştır (2, 11). Bu çalışmada Aile Hekimliği Polikliniği'ne başvuran 177 hastada sigara içme durumlarıyla tanıtıcı özellikleri arasındaki ilişkiler gözden geçirilmiştir. Konuyla ilgili gelecek araştırmalarda sigara içme davranışını etkileyen psikososyal ve kültürel faktörlerin incelenmesinde yarar olacaktır. Aile hekimliği uygulamalarının sigara sorunu ile mücadelede farklı değişkenleri dikkate almasını sağlayan veriler zenginleştirilmelidir.

\section{KAYNAKLAR}

1. Teneggi $V$, Squassante $L$, lavarone $L$, Milleri S, Bye A, Gomeni R. Correlation and predictive performances of saliva and plasma nicotine concentration on tobacco withdrawal-induced craving. British journal of clinical pharmacology. 2002;54(4):407-14.

2. Şengelen M. Hacettepe Üniversitesi Onkoloji Hastanesi Sigara Bırakma Ünitesi'ne ocak 2007-aralık 2009 tarihleri arasında başvuran bireylerin bazı özellikleri ve sigara bırakma olasılıkları: Ankara : Hacettepe Üniversitesi Sağlık Bilimleri Enstitüsü, 2011.; 2011.

3. Karlıkaya C, Öztuna F, Solak ZA, Özkan M, Örsel O. Tütün kontrolü. Toraks Dergisi. 2006;7(1):51-64.

4. Örsel O, Örsel S, Alpar S, Uçar N, Güven SF, Şipit T, et al. Sigara bırakmada nikotin bağımlılık düzeylerinin tedavi 
sonuçlarına etkisi. Solunum Hastalıkları. 2005;16(3):112-18.

5. Coşar B, Şahin K, Arıkan Z, Işık E. Nikotin bağımlıı̆̆ı, psikofarmakolojisi, bağımlılık davranışının bazı psikiyatrik bozukluklarla ilişkisi. 3P Dergisi 1996; 4: 199-205. Relationship of Nicotine Dependency, Psychopharmacology and Dependency Behavior with Some Psychiatric Disorders.

6. Birligi AP. Psikiyatride hastaliklarin tanimlanmasi ve siniflandirilmasi el kitabi. Yeniden gözden geçirilmis dördüncü baski (DSM-IV-TR), Washington, DC, Amerikan Psiki-yatri Birligi, E Köroglu (Çev), Ankara, Hekimler Yayin Birligi. 2001.

7. Sahin S, Ozdemir K, Unsal A. Evaluation of the relation between smoking frequency, smoking addiction and depression in university students. HealthMED. 2014;8:483-92.

8. Drope J, Schluger N, Cahn Z, Drope J, Hamill S, Islami $F$, et al. The Tobacco Atlas. Atlanta: American Cancer Society and Vital Strategies.2018.

9. Araştırması KYT. Türkiye Halk Sağlığı Kurumu. TC Sağlık Bakanlığı Yayın. 2012(948).

10. Bilir N, Özcebe H, Ergüder T, MauerStender K. Tobacco control in Turkey: story of commitment and leadership. Copenhagen, Denmark. 2012.

11. Çelepkolu T, Atli A, Palancı Y, Yılmaz A, Demir S, İbiloğlu AO, ve diğ. Sigara kullanıcılarda nikotin bağımlılık düzeyinin yaş ve cinsiyetle ilişkisi: Diyarbakır örneklemi. Dicle Tıp Dergisi. 2014;41(4).

12. Sunay D, Sivri F, Dilbaz N, Şengezer T. Ankara ili Yenimahalle ilçesinde birinci basamak sağlık kuruluşuna başvuran bireylerde tütün bağımlılığı ve ilişkili risk faktörleri. Türkiye Aile Hekimliği Dergisi. 2014;18(1):42-8.

13. Özşahin $K$, Ünsal $A$, Erdoğan $F$, Gereklioğlu Ç, Bakar C, Tokalak I. Sigara bırakma üzerinde etkili faktörler: aile hekimliği poliklinik hastaları üzerinde bir çalışma. TAF Prev Med Bull. 2007;6(3):181-6.

14. Zincir SB, Zincir N, Sünbül EA, Kaymak E. Sigara bağımlıı̆ğında mizaç ve karakter özelliklerinin bağımlııı düzeyleri ile ilişkisi. Journal of mood Disorders. 2012;2(4):160-6.

15. Karadağlı F, Nahcivan N. Sigara içen bireylerde sigara bırakmaya hazıroluşluk durumu ile ilişkili faktörler. Dokuz Eylül Üniversitesi Hemşirelik Yüksekokulu Elektronik Dergisi. 2012, 5 (1), 8- 15

16. Kutlu R, Çivi S. Konya İli Lise Öğretmenlerinin Sigara İçme Sıklığı ve Etkileyen Faktörler. TSK Kor Hek. 2007;6:273-8.

17. Akpınar E, Saatçi E, Ergun G, Bozdemir $\mathrm{N}$, İnan S. Çukurova Üniversitesi birinci sınıf öğrencilerinin sigara içme davranışları ve uyum özellikleri. Türkiye Aile Hekimliği Dergisi. 2007;8(2):63-8.

18. Yengil E, Çevik C, Demirkıran G, Akkoca AN, Özler GS, Özer C. Tıp fakültesi öğrencilerinin sigara içme durumu ve sigara ile ilgili tutumları. Konuralp Tıp Dergisi. 2014(3):17.http://dx.doi.org/10.18521/ktd.34618

19. Kutlu R, Marakoğlu K, Çivi S. Selçuk Üniversitesi Tıp Fakültesi hemşirelerinde sigara içme durumu ve etkileyen faktörler. Cumhuriyet Üniversitesi Tıp Fakültesi Dergisi. 2005;27(1):29-34.

20. Tezcan S, Yardım N. Türkiye'de çeşitli sağlık kurumlarında doktor, hemşire ve tıp fakültesi öğrencilerinin sigara içme boyutu. Tüberküloz ve Toraks Dergisi. 2003;51(4):390-7.

21. Mevsim V, Dontlu Ç, Yeniçeri N, Özçakar N, Güldal D. Birinci basamak sağlik hizmeti çalişanlari sigara ve kanser riski konusunda ne biliyor ve ne yapiyor? Journal of Dependence. 2005;6:65-75.

22. Öztürk Özer $A$, Ünalacak M, Ünlüoğlu İ. Sigara ile ilgili yasal düzenlemenin sağlık personelinin sigara kullanımına etkileri. Avrasya Aile Hekimliği Dergisi. 2013;2(3):127-32. 
23. Uysal M, Kadakal F, Karşıdağ Ç, Bayram N, Uysal Ö, Yılmaz V. Fagerström nikotin bağımlılık testinin Türkçe versiyonun güvenirliği ve faktör analizi. Tuberk Toraks. 2004;52:115-21.

24. Buzgan $T$, Çom $S$, Irmak $H$, Baykan $H$, Aydın E, Taner S. Mpower tütün salgınını kontrol etmeye yönelik politika paketi. Sağlık bakanlığıdünya sağlık öğrgütü, ankara. 2007.

25. Alışkanlıkları PS. Sigara ile Mücadele Kampanyası Kamuoyu Araştırma Raporu. PIAR, Ocak. 1988.

26. Atılgan $Y$, Gürkan S, Şen E. Hastanemizde çalışan personelin sigara içme durumu ve etkileyen faktörler. Turk Toraks Dergisi/Turkish Thoracic Journal. 2008;9(4). 